Publicación del Seminario "Ángel González Álvarez" de la Fundación Universitaria Española

Número monográfico sobre Mujer y cambio social Año 2021

\title{
Simone Weil: experiencia, reflexión y acción de una mujer en la guerra
}

\author{
Simone Weil: experience, reflection and action \\ of a woman at war
}

MARÍA DEL SOL ROMANO

Universidad Iberoamericana. Dpto. Humanidades

Puebla. México

ID ORCID 0000-0001-9800-7240

msromano.09@gmail.com

Recibido: 31-10-2021 | Revisado: 11-11-2021

Aceptado: 12-11-2021 | Publicado: 30/12/2021

DOI: https://doi.org/10.51743/cpe.258

RESUMEN: La experiencia de Simone Weil en la guerra la llevó a reflexionar sobre los efectos destructivos de la barbarie. Para ella, la barbarie genera complicidad y cuando se tiene el apoyo de un grupo, es posible matar a otros sin ningún cargo de conciencia. Mediante la barbarie se intenta proyectar una grandeza que se considera absoluta, pero que en realidad es falsa. Para ello, se usan diversos instrumentos de dominio, que hacen creer a uno mismo y a los otros que se tiene un poder y una fuerza ilimitados. Para resistir a la barbarie y hacer frente a la idolatría de la fuerza, la filósofa francesa planea formar un cuerpo de enfermeras de primera línea, que es impulsado por una auténtica inspiración religiosa. La presencia femenina en los 
lugares de mayor peligro sería, principalmente, una importante propaganda en acción, capaz de golpear la imaginación. Asimismo, sería un símbolo de sacrificio, de resolución, de ternura materna, de compasión y de humanidad.

PALABRAS ClAVE: Barbarie, guerra, resistencia, símbolo, Simone Weil.

ABSTRACT: Simone Weil's experience of war led her to reflect on the destructive effects of barbarism. For her, barbarism generates complicity and when one has the support of a group, it is possible to kill others without any charge of conscience. Barbarism is an attempt to project a greatness that is considered absolute, but which in reality is false. To do so, various instruments of domination are used, which make oneself and others believe that one has unlimited power and strength. To resist barbarism and confront the idolatry of force, the French philosopher plans to form a body of front-line nurses, which is driven by a genuine religious inspiration. The female presence in the points of greatest danger would be, above all, an important propaganda in action, which could strike the imagination. It would also be a symbol of sacrifice, resolution, maternal tenderness, compassion and humanity.

KEYWORDS: Barbarism, war, resistance, symbol, Simone Weil.

\section{INTRODUCCIÓN}

- imone Weil $^{1}$ (1909-1943) vivió las dos guerras mundiales del siglo XX, pero una experiencia que le causó un gran impacto fue cuando participó en agosto de 1936 en la Guerra Civil española, al lado del bando republicano, en la columna Durruti. Esta experiencia fue para ella una importante fuente de reflexión ${ }^{2}$, que la llevó posteriormente a pensar con mayor profundidad sobre la cuestión de la barbarie. Esto la inspiró también a elaborar un plan de acción para resistirse eficazmente a ella, concretamente tras el inicio de la Segunda Guerra Mundial.

${ }^{1}$ En adelante se escribirá a lo largo del texto "Weil", salvo en los títulos de libros y artículos, así como en las citas textuales que hagan referencia al nombre completo de la autora.

${ }^{2}$ La experiencia que tiene Weil en la guerra de España será una importante fuente de reflexión sobre la guerra y la barbarie, aunque no la única. Por ejemplo, desde inicios de los años 30 hay escritos suyos sobre este tema, como es el caso de sus "Réflexions sur la guerre" (Weil, 1988, pp. 288-299). 
En 1940 el ejército alemán ocupa París, por lo que Weil y su familia se dirigen a la zona no ocupada y se instalan en Marsella. En 1942 la filósofa viaja con sus padres a Nueva York para ponerse a salvo del antisemitismo. Como se verá más adelante, Weil no es indiferente al sufrimiento de sus semejantes y no puede permanecer cómodamente en la retaguardia. En realidad, ella aceptó partir con sus padres a América confiando en que desde allí podría desplazarse a Londres para participar activamente en la guerra y estar al lado de sus compatriotas.

En una carta que escribe a Maurice Schumann desde Nueva York, le expresa lo difícil que le fue partir, pero que lo hizo "con la esperanza de tener una mayor y más efectiva participación en los esfuerzos, peligros y sufrimientos de esta gran lucha" (Weil, 1957, p. 186) ${ }^{3}$. Como todos sus intentos para viajar a Londres fueron vanos, en esa misma carta le pide ayuda a Schumann diciéndole: "creo realmente que puedo ser útil. Y recurro a usted como camarada para que me saque de la situación moral tan dolorosa en la que me encuentro" (Weil, 1957, p. 187). Gracias al apoyo del político francés, Weil logra llegar a Londres en diciembre de 1942, su plan es poner en marcha su proyecto de formar un cuerpo de enfermeras de primera línea ${ }^{4}$.

En su proyecto, Weil dirige una mirada profunda al impacto que puede suscitar la presencia de la mujer en la guerra, pero no en cualquier lugar, sino en la zona de mayor riesgo. Esto no implica, sin embargo, identificarla como una feminista militante. Cuando la autora reflexiona, por ejemplo, sobre cuestiones como la opresión social y la barbarie, no se refiere a un género determinado, sino que piensa desde una perspectiva neutra y universal. El hecho de que, en comparación con el conjunto de su obra, proyecte

\footnotetext{
${ }^{3}$ Para este artículo se han utilizado algunas ediciones antiguas de la obra weiliana en francés, así como los tomos y volúmenes de la edición crítica francesa publicados bajo el nombre de Euvres complètes. Las obras en francés han sido traducidas al castellano por cuenta de la autora de este artículo.

${ }^{4}$ Weil aspiraba a ser miembro de este grupo de enfermeras, pero, cuando llega a Londres, no se le permite llevar a cabo su proyecto, sino que es enviada a la Direction de l'Intérieur de la Francia libre para trabajar como redactora, lo que le causa una terrible desilusión. Luego, "la alimentación insuficiente y el trabajo excesivo, junto con la pena, había finalmente dado lugar [...] a una enfermedad" (Pétrement, 1973, p. 671). Esto es, Weil enferma de tuberculosis y muere de un fallo cardiaco el 24 de agosto de 1943.
} 
formar un pequeño grupo integrado solamente por mujeres, es algo único y muy significativo.

Para Weil, es esencial que las mujeres que conformaran este grupo tuvieran las cualidades apropiadas para realizar esta peligrosa misión. Asimismo, plantea que "no hay ninguna razón para considerar la vida de una mujer [...] como más valiosa que la vida de un hombre; y con mayor razón si acepta el riesgo de muerte" (Weil, 2008, p. 404). No obstante, con esto no indica que estas mujeres hagan un sacrificio innecesario o suicida, sino que ellas, al igual que los hombres, son completamente capaces de comprometerse en una situación extrema y urgente, como es el caso de la guerra.

Si bien Weil ve en este grupo de mujeres todo el potencial para estar al lado de los soldados, su función y sus propósitos son distintos. Ellas estarían desarmadas, pero su participación en el frente tendría varias ventajas desde el punto de vista material, psicológico, moral y espiritual. A este respecto, debe subrayarse la experiencia que tuvo Joë Bousquet en 1918, durante la Gran Guerra, cuando un grupo de mujeres se encargaba de recoger a los heridos. En una carta que el poeta francés escribe a Weil en 1942, en respuesta al proyecto pensado por la autora, confirma el consuelo que la presencia femenina puede aportar a los soldados heridos en la guerra y reconoce "el impulso que estas presencias femeninas transmitieron a [los] combatientes" (Bousquet, 2008, p. 445).

El presente artículo tiene dos objetivos, por un lado, poner de relieve la experiencia y la reflexión que hace Weil sobre la barbarie. Y, por el otro, destacar que el papel de la mujer en su proyecto de formar un cuerpo de enfermeras de primera línea es fundamental para hacer frente a la fuerza bruta y a la violencia. Por ello, en primer lugar, se hablará de la experiencia que tiene Weil concretamente en la Guerra Civil española. Luego, se verá que la barbarie es un uso desenfrenado de la fuerza. Posteriormente, se verificará que, para proyectar en el mundo una falsa imagen de poder y grandeza, se recurre a diversos instrumentos de dominio. Y, por último, se mostrará que el proyecto weiliano de formar un grupo de enfermeras de primera línea, es una tentativa de responder a la barbarie a través de la acción de estas mujeres que constituyen un símbolo de resolución y de ternura. 


\section{LA EXPERIENCIA DE LA GUERRA}

Weil (1999) despreciaba la guerra, pero lo que le causaba "más horror en la guerra es la situación de los que se encuentran en la retaguardia" (p. 406). Cuando en julio de 1936 estalla la Guerra Civil española, la autora se da cuenta de que no podía permanecer cómodamente en Francia, ya que moralmente se sentía partícipe de ella. En una carta que dirige en 1938 al escritor francés Georges Bernanos, le explica que decidió partir en agosto a España para comprometerse en la guerra porque, como indica, "no podía evitar participar moralmente en esta guerra, es decir, desear todos los días, a todas horas, la victoria de unos y la derrota de los otros, me dije que París era para mí la retaguardia" (Weil, 1999, p. 406).

Weil no se compromete en la guerra con la finalidad de ser una simple observadora, defender una ideología, apoyar los ideales de un grupo o combatir, sino que le impulsa la necesidad de estar al lado de quienes formaban parte de los estratos sociales más desfavorecidos. Como ella misma declara: "desde la infancia, mis simpatías se han dirigido hacia los grupos que se identificaban con los estratos despreciados de la jerarquía social [...] El último que me había inspirado alguna confianza era la CNT española" (Weil, 1999, p. 405). No obstante, en el corto tiempo que pasó en España, Weil se encontró con una guerra llena de crueldad y odio en los dos bandos. Por ello, afirma que "se parte como voluntario, con ideas de sacrificio, y se cae en una guerra que parece una guerra de mercenarios" (Weil, 1999, p. 409). Esto es, la autora determina que la barbarie no solamente estaba en el bando enemigo, sino también en el suyo.

A este propósito, debe señalarse que la postura de Weil, después de su experiencia en la guerra de España, es similar a la de otros pensadores contemporáneos a ella. Un ejemplo es precisamente el caso de Bernanos que estaba en el bando nacional y era militante de L'Action Française. En su obra Les grands cimetières sous la lune (Bernanos, 1938), el escritor denuncia, entre otras cosas, "el horror y la desesperación ante la represión franquista dirigida con la complicidad del clero mallorquín, la proclamación de que esta violencia es el síntoma de una crisis profunda de la civilización occidental" (Mingelgrün, 1987, p. 544). Tras haber leído la obra de Berna- 
nos, Weil le escribe la carta ya mencionada, dado que encontró en dicha obra "ese olor a guerra civil, a sangre y a terror" que ella misma respiró en su propio bando. Pese a que los bandos de Weil y Bernanos eran opuestos, en ambos se derramó inútilmente sangre, se cometieron todo tipo de atrocidades y había una fuerte inclinación a la barbarie.

A partir de su experiencia en España, Weil profundiza su reflexión sobre la cuestión de la guerra y la barbarie. La barbarie es a sus ojos, algo transmisible y cualquiera tiene la tentación de volverse su cómplice, particularmente, debido a la sumisión que se tiene a la opinión colectiva ${ }^{5}$. A saber, "cuando las autoridades temporales y espirituales han puesto una categoría de seres humanos fuera de aquellos cuya vida tiene un precio, no hay nada más natural para el hombre que matar" (Weil, 1999, p. 408). Si se tiene la aprobación y el apoyo de un grupo, puede acabarse con la vida de otros con total naturalidad y sin ningún cargo de conciencia. $Y$ eso es justamente lo que extrae Weil (1999) de su experiencia en la guerra de España: "si por casualidad se experimenta al principio un poco de desagrado, se calla y pronto se lo sofoca por miedo a parecer que se carece de virilidad. Hay ahí un impulso, una embriaguez a la que es imposible resistirse" (p. 408).

Cuando se mata, no importa la vida del otro, sino que se demuestra al propio grupo que se tiene el valor de hacerlo, es una prueba de fuerza y coraje. Como destaca Joël Janiaud (2002), "se puede matar por vanagloria, por virilidad, sin poner atención a la realidad del ser que se suprime" (p. 61). En un conflicto, aunque alguien parezca ser moralmente irreprochable, puede volverse completamente despiadado y violento. Es decir, "personas que repiten sin cesar que son demasiado buenas", en un momento dado pueden llegar a tener "la más fría y la más tranquila crueldad" (Weil, 1989, p. 223). Y esto ocurre primero, por la propia capacidad de cometer el mal y luego, por contarse con el apoyo de una colectividad. En el contexto de la guerra, Weil (1966) notó llevar dentro de sí misma "el germen de todos los crímenes, o de casi todos" (p. 20). Como indica en una carta que dirige al sacerdote dominico Joseph Marie Perrin: "los crímenes me horrorizaban, pero no me sorpren-

${ }^{5}$ Simone Weil utiliza el término platónico de "gran animal" social, para referirse a la influencia que ejerce la colectividad en el individuo, hasta el punto de ser considerada como un absoluto, así como de ver sus opiniones como verdaderas y justas (Weil, 2009, pp. 85-88). 
dían [...] es más bien porque sentía la posibilidad de ellos en mí misma que me horrorizaban" (Weil, 1966, p. 20).

En consonancia con lo anterior, algo que es esencial tomar en cuenta es "la actitud hacia el asesinato" (Weil, 1999, p. 408). Esto es, cuando se mata, no solo se actúa con crueldad, sino que se experimenta una gran indiferencia frente a la muerte de otro ser humano y no se es consciente del mal cometido. Weil (1999), por ejemplo, nunca vio en su grupo "a nadie expresar, ni siquiera en la intimidad, repulsión, desagrado o simplemente desaprobación por la sangre inútilmente derramada" (p. 408) ${ }^{6}$. Al contrario, había un cierto gusto al escuchar o relatar las acciones realizadas, como muestra de compañerismo y de adhesión a los ideales del grupo. A este respecto, Emmanuel Gabellieri (1986) —aludiendo a Weil — afirma que se mata "sin ninguna conciencia moral del asesinato" y esto no se hace "por miedo y necesidad, sino jugando con la vida de otros" (p. 263).

Si se tiene el apoyo de una colectividad se elimina toda la conciencia del mal que se hace a otros y ya no hay discernimiento moral entre el bien y el mal, porque se cree estar actuando con rectitud, ya que, todo lo que determina el propio bando se considera como algo bueno y verdadero, mientras que el bando contrario no solamente es visto como enemigo, sino también como principio de todo mal. Por lo tanto, el individuo cree participar, siguiendo a Domenico Canciani (1990), "en un campo que se autodefine como la región del bien, con lo cual, se libera de la responsabilidad de tener que elegir" (p. 399). Esto conlleva a lo que Weil concibe como una idolatría de lo colectivo que, en última instancia, "fundamenta la barbarie y el despliegue de la fuerza" (Canciani, 1990, p. 399).

A la par de lo dicho hasta ahora, está la cuestión del olvido de los objetivos que están en el origen de un conflicto. Si se recurre a la experiencia de Weil en la guerra de España, ella misma verificó que en el bando en el que se encontraba, las mismas necesidades de la guerra hacían que se descuidaran los ideales que inicialmente impulsaron al grupo a luchar. A saber, "las necesidades de la guerra borran rápidamente el objetivo inicial; obligan a

\footnotetext{
${ }^{6}$ Weil en su proyecto de formar un grupo de enfermeras de primera línea dista por completo de esta actitud. Como se verá más adelante, la misión de este grupo de enfermeras es socorrer a los heridos y moribundos, así como dar consuelo a los que sufren.
} 
olvidar las preocupaciones de justicia, de libertad, de humanidad que habían hecho iniciar esta misma guerra" (Pétrement, 1973, p. 400). Por ello, Weil (1989) observa que los conflictos más violentos de toda la historia de la humanidad se caracterizan por carecer de un "objetivo definible" (p. 49). Y "cuando una lucha no tiene objetivo, no hay medida común, no hay equilibrio, no hay proporción, no hay comparación posible" (Weil, 1989, p. 49). Esto provoca que en una guerra se llegue a responder únicamente a las necesidades del conflicto, se mate y se muera por algo totalmente abstracto, se haga un uso desmedido y desequilibrado de la fuerza.

\section{LA BARBARIE Y LOS INSTRUMENTOS DE DOMINIO}

La barbarie es un uso desmedido de la fuerza que puede "hacer del hombre aún viviente, una cosa" (Weil, 1994, p. 83). Quien está bajo el yugo de la fuerza es visto por el agresor no como un ser humano sino como un objeto sin valor, que en cualquier momento puede ser eliminado o sometido a una muerte en vida. Weil (1994) subraya que es un "estado violento, [una] muerte en vida. El más débil solo tiene la opción entre este estado y el de cadáver" (p. 83). Por su parte, quien hace un uso desmedido de la fuerza, el bárbaro, vive deslumbrado por el poder que siente tener en sus manos. Esto le hace creer que está por encima de los demás y que tiene derecho a decidir sobre la vida y el destino de los otros. Sin embargo, esto no es más que una pérdida del sentido de la realidad que conduce a vivir en un "estado de irrealidad y de sueño" (Canciani, 1990, pp. 399-400). El vivir bajo este estado genera una sensación de superioridad respecto a los demás. Asimismo, impide ver y aceptar la propia fragilidad, una fragilidad que es compartida con todos los seres humanos. En palabras de Weil (1997):

Debido a que toda el alma no ha podido conocer y aceptar la miseria humana, se cree que hay una diferencia entre los seres humanos [...]. Esto se debe a que no se sabe que la miseria humana es una cantidad constante e irreductible y que es en cada hombre tan grande como puede serlo; y que la grandeza proviene de un solo Dios, de modo que hay identidad entre un hombre y un hombre. (p. 336) 
De acuerdo con el planteamiento de Weil, si no se mira en sí esta fragilidad que es común entre los seres humanos, se produce una falsa imagen de uno mismo. Quienes no son capaces de afrontar su propia vulnerabilidad, construyen un "yo" completamente desconectado de la realidad, que se siente superior a los demás y que espera alcanzar el poder absoluto. Esto puede suceder, en particular, con una nación que se concibe a sí misma "elegida" para expandir su poder por doquier, por lo que cree tener el derecho de usar la fuerza e incluso la violencia para lograr todos sus propósitos. En tal sentido, Weil (1989) advierte que "una nación solo puede sacar la fuerza para actuar así de la convicción de que ha sido elegida desde la eternidad para ser la dueña soberana de las otras" (p. 192).

Esta convicción lleva a una nación a proyectar la imagen de una fuerza y un poder que considera absolutos y que percibe como un signo de su propia grandeza. Pero, en el fondo, esta fuerza y este poder son irreales y falsos, porque - siguiendo el enfoque de la autora-, la verdadera grandeza es únicamente de origen divino. De ahí que nadie tiene un poder y una fuerza tan brutales como para destruir todo lo que está a su paso. Ninguna nación sería por sí sola capaz de dominar con facilidad a otras que le superan en número. Si se recurre, por ejemplo, a las observaciones que hace Weil (1989) sobre el hitlerismo, para este sería imposible pasar "de una cierta cantidad de poder al dominio universal; porque un solo pueblo no puede dominar a muchos otros con las fuerzas de las que realmente dispone" (p. 191).

El poder, como afirma Weil (1989), es "esencialmente frágil" (p. 64) y quien quiere propagar en el mundo una imagen de poder y grandeza — que en realidad no posee- - tiene que servirse de diversos instrumentos de dominio, que le hacen creer a sí mismo y a los otros que tiene un poder ilimitado. Uno de ellos son las armas que, gracias al desarrollo tecnológico, son instrumentos de destrucción cada vez más especializados ${ }^{7}$. Otro instrumento de

\footnotetext{
${ }^{7}$ No debe culparse a la técnica de las catástrofes ocasionadas en el mundo, sino al uso que se le da. Es decir, el ser humano en su sed de dominio sobre los otros y sobre la naturaleza, es completamente responsable de los desastres que ocasiona y debe asumir las consecuencias de sus actos. Weil (1989) afirma que "[los] instrumentos de destrucción que la técnica ha puesto en nuestras manos [...] no funcionan por sí solos, y no es honesto tratar de culpar a la materia inerte de una situación de la que tenemos plena responsabilidad" (p. 49).
} 
dominio es el uso del terror y del prestigio, por medio de ellos se aparenta tener una gran fuerza destructora para obtener el control. De este modo, a los ojos de Weil (1989), se logra "someter todo por el terror y el prestigio más que por la fuerza efectiva" (p. 179). En el caso de una guerra, el prestigio es un elemento clave, porque no se puede aparecer como débil y frágil ante los enemigos o frente al propio grupo.

Quienes tratan de mostrar a través del prestigio que poseen una enorme fuerza, se sirven de dos elementos: la propaganda y la crueldad. En cuanto a la propaganda, es un elemento clave del prestigio y está estrechamente ligada a la fuerza en el sentido en el que la hace ver como algo real. De ahí que la propaganda y la fuerza "se sostienen mutuamente". Esto es, la fuerza hace de la propaganda algo "irresistible", mientras que esta última hace penetrar en la imaginación "la reputación de la fuerza" (Weil, 1989, p. 196). El poder de la propaganda es tan efectivo que puede convertirse en un importante instrumento de dominio. Por eso, según Michel Narcy (1990), "el dominio no se funda en la fuerza, sino en la propaganda" (p. 419). En cuanto a la crueldad, es un medio para establecer y fortalecer el prestigio. Quien aparenta ser fuerte usa de manera hábil la crueldad para extender el terror por doquier y hacerse propaganda a sí mismo para aparentar ser alguien poderoso. Al igual que la propaganda, la crueldad es un valioso instrumento de dominio cuando se convierte en un método. En palabras de Weil (1989):

La crueldad fría, calculada y que constituye un método, la crueldad que ninguna inestabilidad de humor, ninguna consideración de prudencia, de respeto o de piedad puede mitigar, de la que no se puede escapar ni con el coraje, la dignidad y la energía, ni con la sumisión, las súplicas y las lágrimas, tal crueldad es un instrumento incomparable de dominio. (p. 186)

Bajo esta perspectiva, es imposible librarse de la crueldad. Si se toma en cuenta el análisis de Weil, hay dos elementos que hacen que la crueldad cause a quien la padece una gran repercusión tanto a nivel psicológico como moral. Por una parte, la crueldad se asemeja a las fuerzas de la naturaleza, ya que, es ciega y sorda. Y por otra, se asemeja a la perspicacia y previsión de la inteligencia humana (Weil, 1989, p. 186). La crueldad confunde y desmoraliza, induce a consentir ciegamente y sin obstá- 
culos a todo lo que impone. Porque cuando alguien siente que su vida es amenazada, siguiendo a Weil (1989), "puede volverse más manejable que la materia inerte" (p. 58).

La crueldad es pues, un método psicológico, por el que se busca doblegar la voluntad de los otros para dominarlos. Quien utiliza la crueldad como instrumento de dominio, actúa siempre con cautela y astucia para manipular a su víctima. Una de las tácticas del agresor es, por ejemplo, perdonar la vida de la víctima para aparentar clemencia y generosidad, al igual que inspirarle confianza. De modo que, "suscita la gratitud de todos aquellos que podrían haber sido aniquilados y que no lo fueron, pues esperaban serlo" (Weil, 1989, p. 186). Una forma similar de manipulación es manteniendo a quienes se consideran enemigos entre un estado de terror y de confianza para confundirlos y atacarlos en el momento oportuno. Weil ve claramente esta característica en Hitler, que "en una conversación, formuló perfectamente al respecto la regla a seguir, diciendo que nunca hay que tratar a alguien como enemigo hasta el momento preciso en que se está en condiciones de aplastarlo" (Weil, 1989, p. 197).

Lo anterior muestra que la crueldad y la propaganda son instrumentos de dominio que tienen en el fondo un elemento fundamental: la mentira. La mentira no es simplemente engañar a los otros aparentando ser quien no se es, sino también, es tener una percepción distorsionada de uno mismo. En la guerra, el bárbaro recurre a la mentira disfrazada de verdad para justificar sus acciones y obtener el acuerdo general. Maneja muy bien lo que Weil (1989) denomina el "arte de conservar las apariencias" (p. 194), dado que no solo evita que los demás condenen sus acciones, sino que él mismo está totalmente convencido de estar en lo cierto, que no se equivoca y que está en su derecho de actuar con crueldad.

Para lograr este efecto, observa la autora, "hay que estar realmente convencido de que se tiene siempre la razón, de que se posee no solamente el derecho del más fuerte, sino también el derecho puro y simple, y esto incluso cuando no es así" (Weil, 1989, p. 194). Desde el punto de vista del bárbaro, el enemigo vencido no tiene ningún derecho y su rebeldía merece ser castigada. Y aunque sus acciones sean violentas, no siente culpa, pues las considera como un deber. Manipula de tal manera a sus adversarios, hasta el punto de que ellos mismos pien- 
sen que merecen ser castigados. Para Weil (1989) este era justamente el proceder de los romanos:

Siempre parecía, por sus actos y sus palabras, que Roma castigaba a sus enemigos no por interés o por placer, sino por deber. Conseguía así, por contagio, hacer surgir en cierta medida en sus propios adversarios el sentimiento de que ellos eran rebeldes, lo que constituía una ventaja inestimable. (p. 193)

Luego de lo dicho hasta ahora, sería conveniente preguntarse sobre los mecanismos que tendrían que utilizar quienes están en una situación extrema como la de la guerra y que no luchan con la finalidad de conquistar o de incrementar su poder - lo que fue, por ejemplo, el caso de los nazis-, sino de defender su patria. Probablemente, las necesidades de la guerra podrían conducirlos a servirse de los mismos procedimientos que los agresores, en particular, el uso de la fuerza bruta y una excesiva violencia para poder vencerlos. Pero, en este caso, ¿no habría también una supresión de la conciencia moral cuando se mata al enemigo? Y lo más importante, ¿cómo evitar convertirse en un bárbaro derramando innecesariamente sangre? En tal sentido, sería pertinente recurrir a la contribución que hace Weil al respecto. La autora insiste en buscar un método eficaz, en emplear procedimientos equivalentes a los de los agresores, aunque no idénticos. A su juicio, es preciso encontrar algo nuevo y completamente opuesto a la fuerza destructora y violenta que usan los bárbaros. Weil propone formar un cuerpo de enfermeras de primera línea que, como se verá más adelante, está integrado únicamente por mujeres.

\section{UN PROYECTO DE RESISTENCIA: LA PRESENCIA FEMENINA EN PRIMERA LÍNEA}

En 1940 Weil escribe una primera versión de su "Projet d'une formation d'infirmières de première ligne" ${ }^{8}$, que le servirá de modelo para el proyecto

\footnotetext{
${ }^{8}$ El manuscrito del proyecto escrito originalmente en 1940 está perdido, pero puede encontrarse la versión reescrita que Weil anexa a una carta que envía a Maurice Schumann en
} 
que reescribirá en 1942 en Nueva York y que enviará a distintas autoridades e intelectuales de la Francia libre. En dicho proyecto plantea que un pequeño grupo de mujeres, que tengan conocimientos básicos de enfermería, presten primeros auxilios de manera inmediata a los soldados heridos en combate y asistan a los moribundos ${ }^{9}$. Estas mujeres no están "animadas por el espíritu ofensivo" (Weil, 2008, p. 403) y son completamente capaces de "estar siempre en los lugares más difíciles, para correr tanto o más peligro que el de los soldados que corren más peligro" (Weil, 2008, p. 403).

A los ojos de la autora, las ventajas de formar este grupo de mujeres superan en gran medida las desventajas. Los efectos de su presencia serían significativos y sumamente positivos a nivel material y moral. Desde el punto de vista material, proporcionarían a los soldados heridos cuidados y socorro inmediato que podrían librarlos de una muerte segura. Y, desde el punto de vista moral, además de acompañarlos durante el tiempo que esperan la llegada de los camilleros, su asistencia a través de palabras y acciones sería un consuelo para los soldados afligidos por los horrores de la guerra. De acuerdo con Weil (2008),

Estando presentes en el lugar de mayor peligro, acompañando a los soldados bajo el fuego, cosa que los camilleros, enfermeros y enfermeras ordinarios no hacen, ellas salvarían en muchos casos la vida de los soldados dando a los que caen cuidados sumarios, pero inmediatos. El apoyo moral que ellas aportarían a todos aquellos de los que pudieran ocuparse sería igualmente inestimable. Ellas consolarían las agonías reuniendo los últimos mensajes de los moribundos para sus familias; disminuirían con su presencia y sus palabras los sufrimientos del período de espera, a veces tan largo $\mathrm{y}$ tan doloroso, que transcurre entre el momento de la herida y la llegada de los camilleros. (p. 405)

1942. Se trata de la versión que enviará a diversos intelectuales y autoridades (Weil, 1957, pp. 187-195, 2008, pp. 402-411).

${ }^{9}$ En un anexo de la carta que Weil dirige a Schumann, agrega un extracto del Bulletin of the American College of Surgeons de abril de 1942. Asimismo, indica que, de acuerdo con la Cruz Roja Americana, “el 'shock', la 'exposición' y la hemorragia, que solo pueden remediarse por medio de un tratamiento inmediato, causan en gran medida la mayor proporción de muertes en combate. La Cruz Roja Americana ha desarrollado un sistema de inyecciones de plasma que puede utilizarse en el campo de batalla en casos de shock, quemaduras y hemorragias" (Weil, 2008, p. 411). 
Weil observa con detenimiento las estrategias que usan los agresores y determina que una de las causas del éxito de los nazis es la importancia que estos dan a los factores morales y psicológicos. Esto es, "Hitler nunca perdió de vista la necesidad esencial de golpear la imaginación de todos; de los suyos, de los soldados enemigos y de los innumerables espectadores del conflicto" (Weil, 2008, p. 406). Los nazis emplean las SS como instrumentos de propaganda, que resultan muy eficaces. Se trata de una propaganda que no se reduce a grandes discursos sino a acciones concretas. Los integrantes de estos grupos están preparados para afrontar cualquier riesgo, incluso la muerte y representan un fuerte impacto a la imaginación de quienes conocen sus hazañas. Weil (2008) advierte que son formaciones "constituidas por hombres elegidos para tareas especiales, dispuestos no solamente a arriesgar su vida, sino a morir" (p. 406). Y están resueltos a hacer esto porque "están animados por una inspiración distinta a la de la masa del ejército, una inspiración que se asemeja a una fe, a un espíritu religioso" (Weil, 2008, p. 406).

Weil (2008) declara: "no es que el hitlerismo merezca el nombre de religión. Pero, sin duda, es un ersatz de la religión, y esta es una de las principales causas de su fuerza" (p. 406) ${ }^{10}$. De ahí que es conveniente recordar que a los integrantes de las SS se les inculcaba algo semejante a un espíritu religioso, pues se les presentaba la ideología nazi como un absoluto, como un sustituto mundano de lo divino. Se les formaba ideológicamente para que tuvieran un fervor desmesurado por el partido y para mantener en ellos un espíritu de lucha y de sacrificio de su propia vida. Se despertaba en ellos el odio hacia el bando contrario para que no tuvieran ningún reparo en actuar con una brutalidad sin límites. Por este motivo, siguiendo a la autora, eran completamente "indiferentes al sufrimiento y a la muerte para sí mismos y para el resto de la humanidad" (Weil, 2008, p. 406).

Por ello, para Weil (2008), los aliados tienen la responsabilidad de no contentarse con imitar a los agresores, sino de encontrar métodos equivalentes por medio de los cuales se golpee la imaginación, pero de una forma nueva, "porque cuando se trata de golpear la imaginación, cualquier copia

\footnotetext{
${ }^{10}$ Para Weil la palabra "ersatz" tiene el sentido de "sustituto". En este contexto, el hitlerismo pretende presentarse como algo absoluto, así como un sustituto de una religión auténtica, aunque, en el fondo, no es más que una falsa imitación de una religión.
} 
carece de objetivo. Solo lo nuevo golpea" (p. 406). Y esta facultad de hacer surgir lo nuevo "es por sí misma un signo de vitalidad moral capaz de sostener las esperanzas" (Weil, 2008, p. 406). Weil propone su proyecto de enfermeras de primera línea, precisamente con el propósito de mostrar que, además de las ventajas ya señaladas, la presencia de estas mujeres sería un modo más auténtico, novedoso y eficaz de causar una fuerte impresión en el propio grupo, en el bando opuesto y en el resto de los espectadores.

La formación que proyecta Weil está integrada por mujeres que por naturaleza tienen las cualidades morales necesarias para llevar a cabo la misión de estar en las zonas de mayor riesgo. Son mujeres comprometidas, caracterizadas por tener una "resolución fría y viril" unida "con la ternura que requiere el consuelo de los sufrimientos y las agonías" (Weil, 2008, p. 410). Es esencial que actúen con valentía y firmeza ante las adversidades, porque "evidentemente sería indispensable que estas mujeres tuvieran una gran cantidad de coraje. Ellas deberían haber hecho el sacrificio de sus vidas" (Weil, 2008, p. 403).

Lo anterior indica que estas mujeres manifiestan a través de sus acciones no solamente mucho coraje, sino también un espíritu de sacrificio capaz de golpear la imaginación de una manera totalmente nueva. La heroicidad que demuestran al poner en riesgo su vida sería una importante propaganda en el frente. Esto tendría un fuerte impacto por estar fundamentado en actos y no simplemente en palabras. Como observa la autora, "en la retaguardia, la propaganda se hace por medio de la palabra. En el frente, las palabras deben ser reemplazadas por los actos" (Weil, 2008, p. 407).

A diferencia de los agresores, estas mujeres no son movidas por el odio, por un falso espíritu religioso o por la idolatría a una ideología, a un partido o a una nación. A ellas les impulsa algo completamente nuevo y distinto: una verdadera inspiración religiosa, que es "auténtica y pura", que se manifiesta mediante símbolos a través de palabras y, principalmente, de actos (Weil, 2008, p. 407). Y esto es justamente el punto central del proyecto de Weil, que estas mujeres causen un fuerte impacto de carácter simbólico, susceptible de resistir a la extrema violencia y barbarie de los agresores. Estas mujeres, no solamente serían un gran apoyo material, psicológico y moral, sino también espiritual. Son un símbolo de humanidad y de ternura ante la extre- 
ma violencia, crueldad y salvajismo que se vive en el campo de batalla. Como destaca Weil (2008):

Ningún símbolo puede expresar mejor nuestra inspiración más que la formación femenina aquí propuesta. La simple persistencia de algunos oficios de humanidad en el centro mismo de la batalla, en el punto culminante del salvajismo, sería un desafío rotundo a ese salvajismo que el enemigo ha elegido y que a su vez nos impone. El desafío sería tanto más impactante cuanto que estos servicios de humanidad serían realizados por mujeres y estarían envueltos por una ternura maternal. (p. 408)

En efecto, mientras los agresores, concretamente los jóvenes SS, tienen un coraje "de una especie brutal y baja; [que] procede de la voluntad de poder y de destrucción" (Weil, 2008, pp. 407-408), el coraje del grupo de enfermeras que plantea Weil es de otra naturaleza. Estas mujeres no intentan mostrar su coraje realizando una cantidad desenfrenada de acciones destructivas y violentas. Tampoco buscan impactar al mundo probando que son mejores o más valientes que los integrantes del bando opuesto, procediendo con la misma violencia o aumentando su nivel de brutalidad. Ellas están desarmadas y no están animadas por el odio o por el deseo de matar, lo que las hace diferentes de los agresores es la compasión, la resolución y la ternura que muestran en el frente. Sus acciones son heroicas y representan una nueva forma de golpear la imaginación de una manera efectiva y profunda. De modo que "este cuerpo, por un lado, y las SS, por otro, harían con su oposición una imagen preferible a cualquier eslogan. Sería la representación más contundente posible de las dos direcciones entre las que la humanidad debe elegir ahora" (Weil, 2008, p. 408).

\section{CONCLUSIÓN}

En virtud de lo expuesto a lo largo de este artículo, puede decirse que, en una situación tan radical como la de la guerra hay una fuerte tendencia a volverse cómplice de la barbarie. Además de que el odio, la sed de dominio y de triunfo impulsan a terminar con total naturalidad con la vida de aquellos que se consideran enemigos, se olvidan o se dejan de lado los verdaderos moti- 
vos o ideales que impulsan a luchar. Y esto es precisamente lo que observaron Weil y Bernanos a pesar de estar en bandos opuestos en la Guerra Civil española. La barbarie no solo tiene una causa colectiva, sino que también es el efecto de una profunda decadencia espiritual. Por un lado, es muy difícil evitar dejarse llevar por los sentimientos colectivos y se actúa de acuerdo con los parámetros del grupo, incluso si este induce al derramamiento de sangre, al odio y a la supresión de la conciencia moral.

Por otro lado, el hecho de tener, siguiendo a Weil (1989), "una conciencia tan impenetrable a la verdad implica un envilecimiento del corazón y del espíritu que obstaculiza el pensamiento" (p. 195). Se hace uso de la fuerza y la violencia por una voluntad de dominio, al igual que para probar al mundo un poder y una grandeza, que en verdad no se tienen, porque, como se ha dicho más arriba, la verdadera grandeza es únicamente de origen divino. Ante este escenario, podría creerse que es imposible resistirse a la barbarie y a la tentación de conseguir un poder que se considera absoluto y con el que se alcanzaría la grandeza.

El proyecto que piensa Weil de formar un cuerpo de enfermeras de primera línea es un verdadero esfuerzo de resistencia a la violencia, al sufrimiento, al odio y a la brutalidad. A primera vista, este proyecto - que no se le permite llevar a cabo- ${ }^{11}$, parece ser demasiado arriesgado, poco práctico y nada realista. Probablemente varias personas a las que Weil envió su proyecto pensaron que no tenía sentido poner en semejante peligro la vida de estas mujeres. Asimismo, es posible que creyeran que no era práctico transportar a las zonas de mayor riesgo a este pequeño grupo de enfermeras desarmadas, ya que ocuparían el lugar de soldados y armas que serían más útiles para la guerra.

Sin embargo, la propuesta de Weil no es romántica ni irreal, es un plan de acción que debe usarse en una situación extrema. Es un combate contra el totalitarismo, la barbarie, la fuerza bruta y la idolatría de lo colectivo. En palabras de Janiaud (2002) es "una manera de hacer vivir, en las mismas acciones de guerra, una inspiración auténtica, la de un valor moralmente superior al heroísmo fanático de las SS" (p. 122). Se trata de un nuevo tipo

\footnotetext{
${ }^{11}$ Véase nota 4.
} 
de resistencia sin armas, sin violencia, sin fuerza bruta, en donde no se busca el exterminio de los enemigos, sino ser un símbolo de concordia, de consuelo, de humanidad, de compasión, de ternura materna. Este grupo de mujeres es un símbolo de resolución y de amor materno, un amor que es completamente puro, desinteresado, gratuito y que expresa sacrificio y don de sí.

El proyecto de Weil es de gran actualidad en el sentido en el que se necesita de algo que golpee la imaginación de una forma nueva, un símbolo que inspire, que invite a reflexionar, a actuar y a comprometerse con los otros. Es preciso que no solamente en situaciones extremas como la guerra sino, en cualquier circunstancia, haya personas capaces de socorrer, consolar y construir vínculos entre los seres humanos.

\section{REFERENCIAS BIBLIOGRÁFICAS}

Bernanos, G. (1938). Les grands cimetières sous la lune. Plon.

Bousquet, J. (2008). Lettre de Joë Bousquet sur le "projet d'une formation d'infirmières de première ligne". En $\mathrm{S}$. Weil, Euvres complètes, $t$. IV, vol. 1 (pp. 444-446). Gallimard.

Canciani, D. (1990). Les guerres d'Espagne de Simone Weil. Cahiers Simone Weil, XIII (4), 375-403.

Gabellieri, E. (1986). Psychologie du "gros animal" et philosophie de la barbarie chez Simone Weil. Cahiers Simone Weil, IX(3), 260-285.

Janiaud, J. (2002). Simone Weil: L'attention et l'action. Presses universitaires de France.

Mingelgrün, A. (1987). L'écriture polémique/poétique de Georges Bernanos dans 'Les Grands Cimetières sous la lune'. Revue belge de philologie et d'histoire, 65(3), 544-551.

Narcy, M. (1990). Simone Weil dans la guerre, ou la guerre pensée. Cahiers Simone Weil, XIII (4), 413-423.

Pétrement, S. (1973). La vie de Simone Weil. Fayard.

Weil, S. (1957). Écrits de Londres et dernières lettres. Gallimard.

Weil, S. (1966). Attente de Dieu. Fayard.

Weil, S. (1988). Euvres complètes, t. II: Écrits philosophiques et politiques, vol. 1: L'engagement syndical (1927-1934). Gallimard.

Weil, S. (1989). Euvres complètes, t. II: Écrits philosophiques et politiques, vol. 3: Vers la guerre (1937-1940). Gallimard. 
Weil, S. (1994). Euvres complètes, t. VI: Cahiers, vol. 1: (1933-septembre 1941). Gallimard.

Weil, S. (1997). Euvres complètes, t. VI: Cahiers, vol. 2: (septembre 1941 -février 1942). Gallimard.

Weil, S. (1999). Euvres. Gallimard.

Weil, S. (2008). Euvres complètes, t. IV: Écrits de Marseille, vol. 1: Philosophie, science, religion, questions politiques et sociales. Gallimard.

Weil, S. (2009). Euvres complètes, t. IV: Écrits de Marseille, vol. 2: La Grèce, l'Inde et l'Occitanie. Gallimard. 